\section{An intricate web - designing and authoring a web-based course}

\author{
P. A. Reynolds, ${ }_{1}^{1}$ J. Harper, ${ }^{2}$ R. Mason, ${ }^{3}$ M. J. Cox $^{4}$ and K. Eaton ${ }^{5}$
}

IN BRIEF

- Outlines the educational and technical factors that have to be considered when designing and authoring a web-based course.

- Describes the advantages and strengths of web-based courses but stresses that it is essential to ensure that educational need has priority over technological excellence.

- Recent developments in online education for medicine and dentistry are considered.

The Internet offers a great opportunity to deliver dental education in new ways. However, to achieve the maximum benefit from this medium, it is necessary to understand its strengths and weaknesses and, above all, not to lose sight of the key principle that in education it is the message and not the messenger (the content and not the medium) that should be given priority. After a brief introduction, this paper considers the principles of designing online programmes. It stresses the need for ensuring that students have easy access to the materials that have been designed and then describes 'learning objects' and virtual learning environments (VLEs). It concludes that with some notable exceptions, dental educators have hardly begun to grasp the benefits of web-based teaching and learning.

\section{E-LEARNING IN DENTISTRY}

Section A: Teaching and technology

1. A description of the new technologies used in transforming dental education

2. Seeing is believing: dental education benefits from developments in videoconferencing

3. Webcasting: casting the web more widely

4. Top of the pops - CD-ROM and DVDs in dental education

Section B: Informatics: better informed by systems and services

5. Better informed: an overview of health informatics

6. Better informed in clinical practice a brief overview of dental informatics

7. Digital clinical records and practice administration in primary dental care

Section C: Impact of e-learning in

dental education

8. Remember the days in the old school yard: from lectures to online learning

9. An intricate web - designing and authoring a web-based course

10. The many faces of interaction

11. Supporting the learner and teacher online

12. Making a mark - taking assessment to technology

13. Continuing professional development and ICT: target practice

14. Assuring quality

Section D: A connected future

15. Nine years of DentEd: a global perspective

16. A vision of dental education in the third millenium

\section{INTRODUCTION}

The use of the web as an educational resource and as a mode of teaching and learning brings with it a new range of demands and disciplines. These are not just concerned with the technology, but should be driven by educational needs. A fundamental issue is how webbased materials and courses are created and deployed to enhance teaching and learning.

Successful employment of educational materials on the web is the role of instructional designers who have knowledge of

\footnotetext{
1*Professor of Dental Education, Centre for Flexible Learning in Dentistry, King's College Dental Institute, Floor 3, Strand Bridge House, 138-142 Strand, London, WC2 $1 \mathrm{HH} ;{ }^{2}$ TT Manager, The Dental Institute at Guy's, King's and St Thomas' NHS Hospitals, King's College Hospital, Denmark Hill, London, SE5 9RW; ${ }^{3}$ Professor of Educational Technology, Institute of Educational Technology, The Open University, Walton Hall, Milton Keynes, MK7 6AA; ${ }^{4}$ Emerita Professor of IT in Education Department of Education and Professional Studies, School of Social Science and Public Policy, King's College London/Senior Research Fellow, King's College London Dental Institute, Floor 3, Strand Bridge House, 138-142 Strand, London, WC2 8LD; ${ }^{5}$ Visiting Professor, UCL Eastman Dental Institute, 256 Gray's Inn Road, London, WC2 1 HH/Honorary Professor, University of Kent ${ }^{*}$ Correspondence to: Professor P. A. Reynolds Email: P.A.Reynolds@kcl.ac.uk
}

\section{Refereed Paper}

DOI: 10.1038/sj.bdj.2008.351

${ }^{\circ}$ British Dental Journal 2008; 204: 519-524 web design or web-authoring (the terms appear to be interchangeable). One limited definition is 'a flexible way to represent and encode learning materials. ${ }^{1}$ However, the focus should always be on educational considerations and not the mechanics of the web. This paper therefore places the emphasis on those topics affecting course compilation, design, content and material together with the influence of these on teachers and students, rather than on the mechanics of web design and authoring. Likewise the minefield of issues relating to copyright, consent and costings is beyond the scope of this paper.

Does e-learning demand a new approach to the design and production of educational courses and teaching material? The content and the learning outcomes may remain the same as for classroom-based education or paper-based distance learning, it is the delivery method, graphical presentation, instructional design and cognitive interaction that change - in short, the conceptual design. ${ }^{2}$

Web-based courses should be student-centred, not teacher-centred. An advantage of this medium is that course creators can now focus on the needs and support of students (and staff), not just 
the instructional design and pedagogical characteristics of the software used in the creative process, such as how to convert files into web format and include images and videos.

Probably the most challenging aspect is to be innovative and adventurous by challenging students in ways that cannot be achieved in a lecture. There can be much more accountability and recording of what students do through online tests and assessments. However, in a practical course such as dentistry, the most powerful method is a blended approach, relating the online to practical and clinic case-based scenarios, so that the courses - and the students - work seamlessly between clinics and online. ${ }^{3}$

Some commentators require more evidence for the advantages of online teaching - "the use of new media must first also be shown to be superior to traditional teaching of topics such as the provision of specialist teaching if they are to prevail. ${ }^{4}$ However, there are clear advantages, including those of interactivity and the uses of links to multiple media representations and feedback. Hypertext and hypermedia bring new possibilities to course creation as they allow 'the text to branch in several directions at once, representing many relevant paths of thought. ${ }^{5}$

\section{PUTTING IT TOGETHER}

As already emphasised, 'Good course design is a skill independent of any technological media. Elements include careful curriculum choice and a wellplanned path through the content to meet the learning objectives. ${ }^{6}$ It is more than just putting a PowerPoint presentation online; nor is it simply a matter of converting 'paper or word processed documents into HTML', as 'appropriate use of web materials usually implies a review of the materials and the learning that they are intended to facilitate. The interface should be clear and intuitive, appropriately accredited and the results easy to use. ${ }^{1}$

The process of designing a web-based course starts in exactly the same way as a traditional course - with the proposed learning outcomes, establishing the learning objectives, and in the knowledge of students' needs and support and that of all staff involved. It is, as Wiesenberg and Stacey ${ }^{7}$ have commented, 'a complex one, depending on several intersecting factors and strongly influenced by intangible variables that often become apparent only after the initial design process is completed and programme facilitation is underway."

In their view there are five central themes relating to programme design:

- The need to spend considerable time in the pre-delivery phase of programme design

- The 'apparently' more complex nature of teaching in a more complex online learning environment

- The effect of different communications media on communication dynamics

- The value of asynchronous communication for in-depth critical reflection and analysis

- The importance of empowering students to take responsibility for their learning.

\section{THE KEYS}

Key considerations in developing a successful website and web-based course are usability and accessibility. It is claimed that usability is about quality, ie a website with high usability is "intuitive and user-friendly." Accessibility, on the other hand, is "about increasing the number of users by making sure the website can be used by everyone regardless of any disability or any technological disadvantage. ${ }^{8}$ Adjunctive use of CDROM or print may well be valuable.

Much of the debate about usability is concerned with writing for the web, ie the creation and display of text. The nature of the web means its impact is different from printed material. As a visual rather than a literal medium, it is, unlike a book, not suitable for showing large amounts of text. Tests have shown that 'People rarely read web pages word by word; instead they scan the page picking out individual words and sentences. ${ }^{9}$ As a result, the same authority recommends that a web-author should "write no more than $50 \%$ of the text you would have used in a hard copy publication, ${ }^{10}$ not least because, as others have observed, 'reading from computer screens is about $25 \%$ slower than reading from paper.'
The benefit of following such precepts is illustrated by a study ${ }^{9}$ in which five different presentational styles (promotional, concise, scannable, objective and combined) and text were developed. Each contained the same basic information, different wording, but the same site navigation; users had to perform the same tasks at each of the sites.

The measured usability (based on the performance metrics of time, errors, memory and site structure) was much higher for the concise version (58\% better) and for the scannable version (47\% better). Further, when the three ideas for improved writing style (concise, scannable, and objective) were combined in the fifth version of the site, the improvement was even more impressive - up to $124 \%$ better.

It is worth considering carefully the structure of the site in terms of navigation and e-content. As has been said earlier, it is not just a question of posting a PowerPoint presentation and some course notes on a website. The course site has to appear interesting, easy-to-use and easy-to-understand, and look attractive, thereby engaging students and retaining their attention and interest. Factors that contribute to a poor look-and-feel include the choice of inappropriate colour combinations such as black type on a red background, which is often unreadable, and too small a type face.

On a practical level, the layout should make the site easy to read and follow. Consideration should be given to alternative versions that cater for disabilities. A poorly-designed site can easily turn off users, or prevent them from obtaining the information they are seeking, not to mention causing eye-strain and headaches. Making it a familiar environment to students helps and the structure could therefore look like a classroom or even a school, with a typical set of resources such as a library, which in a web-based course is a store for information and supporting material and houses the links for accessing external sources.

The design of a course should start with a storyboard, ie the outline of the course objectives, contents and materials, and then a step-by-step approach, ie a logical progression through the course interspersed at the correct points with tests, 
assignments and assessments. A layout grid can be devised to show developers how the course is laid out. This is a useful aid if a number of people are involved as it helps to avoid different design and writing styles from creeping in, though variation can be considered desireable.

The components involved in online course development are summarised in Figure 1.

\section{Accessibility}

Students studying a web-based course need, and should expect, an enhancing experience. Ideally, all information, assignments, tests and assessments should be at the most three clicks away from the home page. ${ }^{8}$ A good site will have a clear navigation and structure so that users will feel they are making progressive steps through the course.

Their experiences of non-educational web use have led students to expect similar performance when they use the web for their education. For example, 'Users do not like waiting for pages to download, ${ }^{8}$ a demand that may constrain the overuse of images, animation and videos.

Course compilers may be using state-ofthe-art systems to create and deliver their course, but can they be fully utilised by the end-users (students), especially those off-campus? As Castro ${ }^{11}$ has reminded us, 'While practically any computer can display webpages, what these pages actually look like depends on the type of computer, the monitor, the speed of the Internet connection, and, lastly, the software used to view the pages and the browser. ${ }^{11}$

The important factor is not the quality of the sound and vision that is transmitted, but the quality that is received. It should also be remembered that computing and telecommunications services differ throughout the world. In the UK, broadband is benefiting e-learning, but it is not yet widely available in all other parts of the world and where it is unavailable, downloading large files is impractical.

A further factor is that computer screens have different resolutions. Web content designed for a specific resolution may look smaller on a higher-resolution screen, but swamp a lower-resolution screen. ${ }^{12}$ Students' computer equipment can also influence the typefonts used for

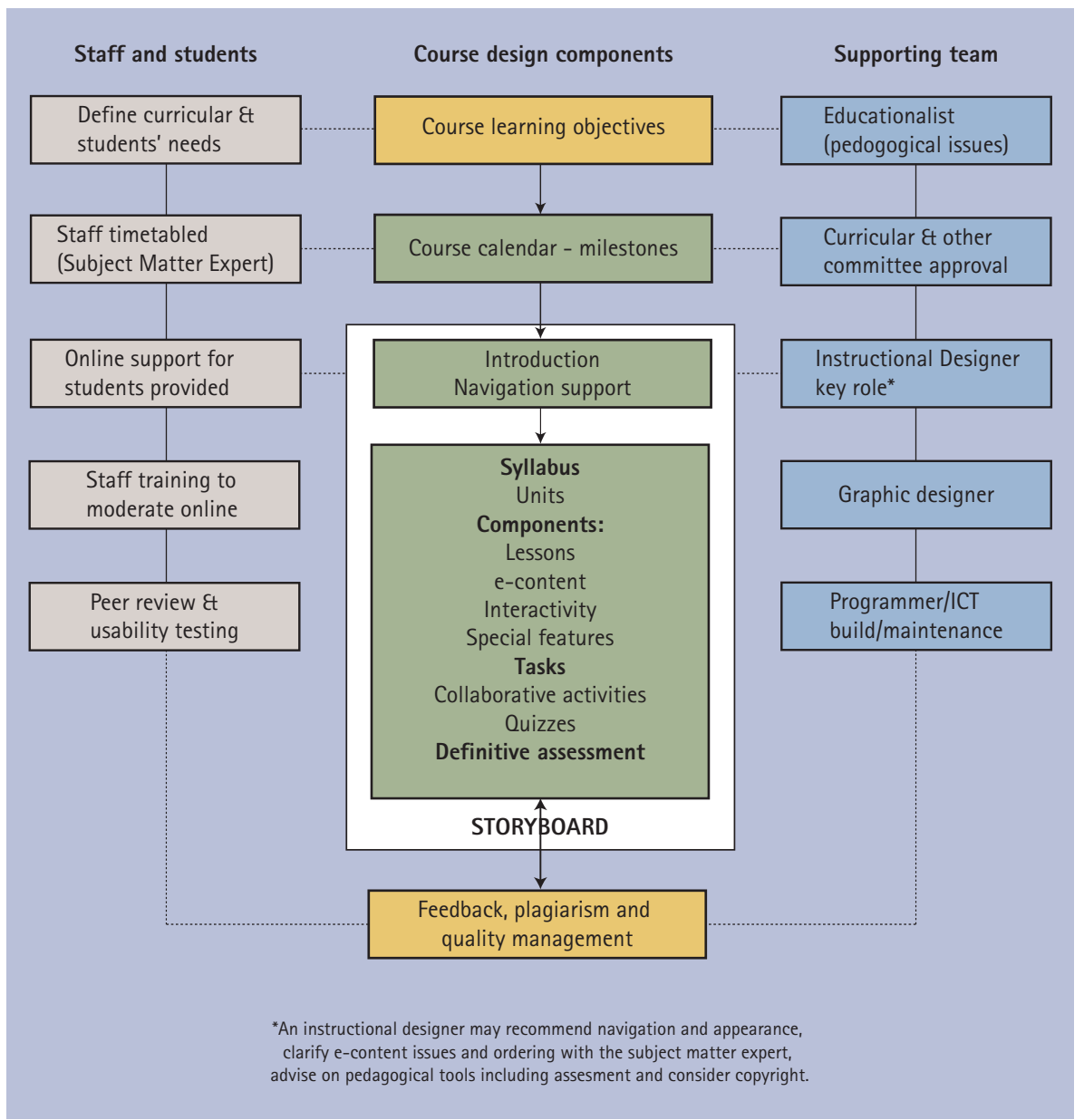

Fig. 1 Framework of components involved in online course development

the text. It may well be pretty or trendy to use the latest style, but if that is not supported by a student's computer it will change to that computer's default font, possibly affecting "the size and spacing of text and images. ${ }^{13}$

\section{THE MEDIA AND THE MESSAGE}

Most tutors and teachers will be experienced in producing material for paperbased courses. Although they are all essentially a mix of images and narrative, web technology does provide improvements by supplying animation, live images and motion pictures (all in colour) that can have a greater impact than the simple stills and text of paper-based material. The media can indeed enhance the message. In addition, it can, to a large extent, replicate the personal involvement of a face-to-face classroom session and, with the advent of virtual reality, the experience of practical training.

There are, of course, drawbacks. Course designers have to be sure that the audience will understand the content, ie they have to be objective not subjective.
There can be no ambiguities as, apart from videoconferencing sessions, there can be virtually no instant feedback or queries from students.

\section{THE OBJECT OF THE EXERCISE}

One element of web-authoring that is attracting considerable attention is 'learning objects'. It has been pointed out they are not new for 'academic libraries (and indeed the whole profession of librarianship is built around the reuse of books, journals and other forms of publication in support of teaching and research).'

However, the web takes this concept to a new level as it can encompass virtually any media, not just the printed form. In this scenario anything from a simple item to a whole course can be considered a learning object, ie anything meaningful that promotes learning. Learning objects can be described as 'small independent chunks of knowledge or interactions stored in a database [that] can be presented as components of instruction or reference information. ${ }^{{ }^{14}}$ 
One of their most significant benefits is the flexibility that they can be used in different ways, but retain the same meaning no matter who is studying them. Apart from their use by course compilers, they can be employed by students "creating webpages for many different tasks, such as in support of project work or as Wikis or as personal blogs, ${ }^{15}$ thus allowing students to establish a personal study programme.

So what form do these learning objects take? Well, any form in reality, for they can be considered as 'any digital resource that can be used to support learning. ${ }^{16}$ In other words, virtually anything that can be accessed via the web - text, photographs, diagrams, webcasts, video clips; the elements that can be used by students as part of their learning process. Although they exist independently, 'They can be grouped into larger collections of content including a traditional course structure. Every learning object can be tagged with Metatags, ie descriptive information allowing it to be searchable by a student. ${ }^{14}$ There is clear institutional gain achieved through reusing these learning objects in different courses. ${ }^{15}$ Translated into forms suitable for medical and dental education, learning objects can be documents from learned articles, pictures, recorded lectures, videos showing real-life treatment and operations, lab tests and previous students' projects. Indeed, it can be argued that they can be anything relevant and useful to a course and its learning outcomes. This does not preclude material specifically generated for a course, although once in existence this becomes a learning object in its own right.

Learning objects that already exist are often held in repositories. Medicine is well-served in this respect. Such libraries include Health Education Assets Library (HEAL) and MededPortal and courses built around reusable learning objects (RLOs), for instance the International Virtual Medical School (IVIMEDS) and the International Virtual Nursing School (IVINURS), as well as more circumscribed projects such as the Universities Medical Academic Partnership (UMAP) ${ }^{16}$ or OCTAVE (a high-level language, primarily intended for numerical

\section{Table 1 Definitions of some different types of learning objects}

\begin{tabular}{l|l|l}
\hline Information object & Knowledge object & Learning object \\
\hline $\begin{array}{l}\text { A piece of information such } \\
\text { as a picture, some text etc. }\end{array}$ & $\begin{array}{l}\text { An information object plus } \\
\text { metadata to place it in a } \\
\text { particular educational context }\end{array}$ & $\begin{array}{l}\text { A knowledge object plus } \\
\text { a learning activity or outcome }\end{array}$ \\
\hline
\end{tabular}

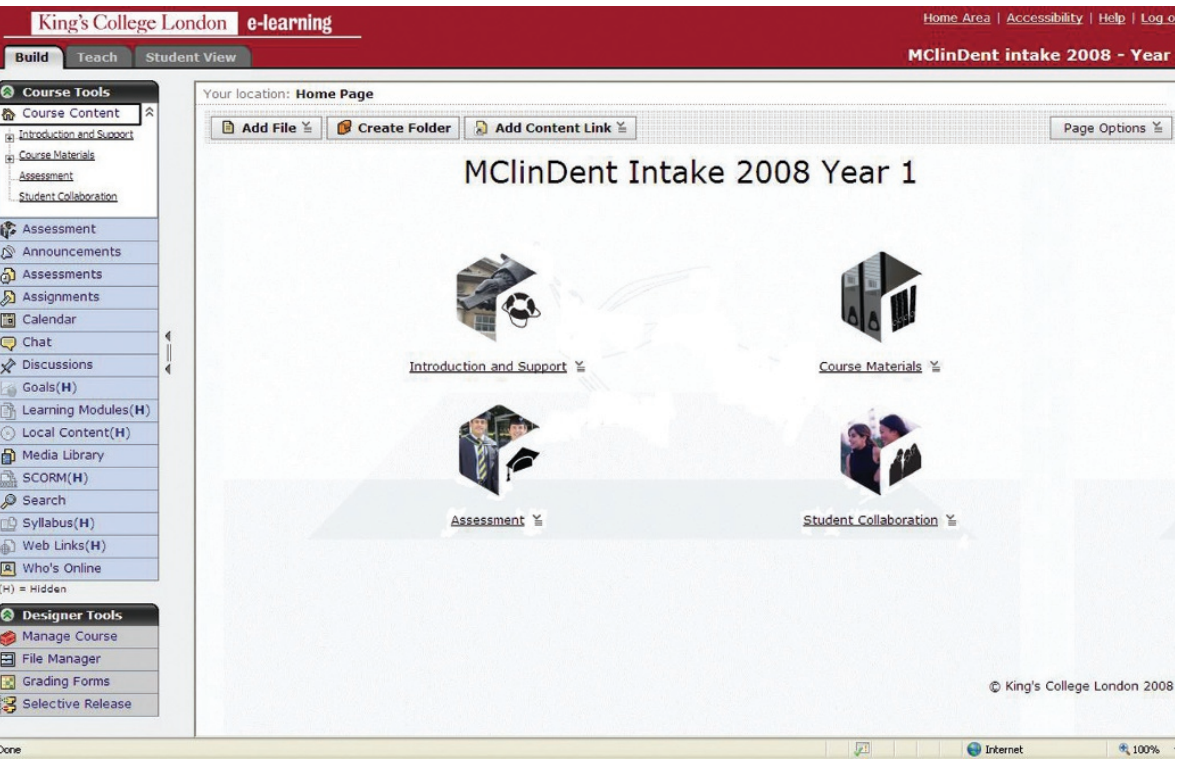

Fig. 2 Screenshot of designer's view of the MClinDent 2008 homepage authored in WebCT Vista 4, showing the course tools available in the left hand column

computations, named after Octave Levenspiel, a famous chemical engineering professor). Of particular interest to dental education is the planned development of the International Virtual Dental School (IVIDENT), which is designed to be specific to dentistry. At a more philosophical level, some have established 'a typology of different objects'16 to clarify the "many definitions of a "learning object" from a whole programme of study down to very specific entities.' The result is a hierarchy of objects as shown in Table 1 .

The main problem with learning objects is one of selection. Traditionally content comes in chunks of learning, which are often several hours long, whereas learning objects, defined as 'a new way of thinking about learning, ${ }^{14}$ are much smaller units, typically ranging from two minutes to fifteen minutes.

\section{GETTING IT TOGETHER}

The learning outcomes have been established, the course structure and content has been decided, the material, possibly in the form of learning objects, has been identified, the test and assignments set: one step remains - how to get it all on the web.

Does the solution depend on the course compiler being a computer buff and web designer? That is one approach, but it does entail a detailed knowledge and experience of a range of computing and web technologies such as the HTML mark-up language and web development, authoring and image-editing tools. Perhaps the more adventurous of compilers might try this approach, but should educationalists be expected to be webexperts as well? Undoubtedly, an understanding of web design and its associated technology should now be one of their attributes. However, it is apposite to note that the Wolfson Reward Programme (a staff development programme) employs a mix of subject experts selected for their teaching excellence and also a number of skilled web developers. ${ }^{18}$

The 'complex nature of a program delivered by advanced communications techniques' ${ }^{18}$ has led one author to recommend 'a centralised team approach to distance programme design that ideally 
includes different professionals to fulfil these functions - subject matter expert or author; graphic designer; web developer; programmer; and instructional designer. ${ }^{19}$ However, he also observes 'More realistically, in most institutional settings online, teachers fulfil all of these functions by themselves. ${ }^{19}$

A team of such people with a mix of pedagogic and web skills, ie the best of both worlds, would seem to be ideal and, no doubt, most commercial courses are developed in this way. In the academic world this is not always possible. There is another solution - the virtual learning environment (VLE), though this does require training and support to use effectively.

Defining a VLE runs into the usual minefield of different and often ambiguous terms with similar meanings which, apart from VLEs, includes managed learning environments (MLEs) and personal learning environments (PLEs). The JISC (Joint Information Systems Committee) Steering Group ${ }^{20}$ recommends that MLEs be seen "to include the whole range of information systems and processes of a college that contribute directly, or indirectly, to learning and learning management.' A VLE on the other hand is seen as a part of an MLE and refers "to the "online" interactions of various kinds which take place between learners and tutors.' These interactions include online learning involving content delivery and traffic. VLEs make use of specific software that establish the interaction and include content delivery and tracking. Elements such as learning resources and student record systems can also be linked into a VLE.

For web-authoring, the benefits of VLEs come through the availability of 'Learning Systems' ${ }^{21}$ that contain a family of software applications that enable course developers to:

- Create powerful learning content using a variety of web-based tools

- Develop custom learning paths for individual students or groups

- Facilitate student participation, communication and collaboration

- Evaluate students' work using a set of assessment capabilities

- Bring top publisher content into elearning.
Within such a system there are authoring tools for developing the course and its ancillary facilities and for loading into the web (Fig. 2). These integral tools allow a wide variety of activities, tools or strategies such as assessment, case studies, self-assessment, group work and problem-based and project-orientated learning. Some also provide pre-prepared content through a suite of online course materials such as video animations and quiz and test banks, without the compiler having to learn new programming tasks.

A major advantage of these systems for educational institutions is that they ensure a common 'look-and-feel' for all courses, irrespective of the departments creating them. However, these communities still enjoy the flexibility of setting their own e-learning policies, working autonomously and setting up repositories of learning objects for their own courses, accessible to others.

Newer universities already have teaching and learning support faculties which facilitate the design and web-authoring and lend support to the teacher and student, whilst maintaining the highest quality of design and production within budget.

\section{The net generation VLE}

There is no doubt that the development of VLEs has changed the way that content can be delivered, but they are built around a teacher-classroom model with an average set of tools, not necessarily the best. It is often difficult to exchange content between them and the graphics design is limited..$^{22}$ The new generation of learners born since 1982 have been described as the 'net generation'. They have grown up in a digital world and are today's graduates. ${ }^{23}$ They are comfortable with the new communications technologies that facilitate the social networking and collective intelligence that is characteristic of the Web 2.0 approach. ${ }^{24}$ The VLE is also evolving to provide a more personalised student experience that incorporates the most appropriate external tools, that has less rigid boundaries, is more social and can even have students as co-creators. Based on the standards-based technology called 'service orientated architecture, the VLE 2.0 has arrived. ${ }^{22}$ The International
Virtual Dental School (IVIDENT) is such a development.

The issues of support and quality and the further development of the web and VLEs are the topics of the subsequent papers in this series.

\section{CONCLUSIONS}

This paper has outlined the educational and technical factors that need to be considered when designing and authoring a web-based course. Unfortunately, with some notable exceptions, dental educators have hardly begun to grasp the benefits of web-based teaching and learning or advantages of a blended (face-to-face and online) mode of delivery.

The next paper in the series will consider the range of different forms of interaction that ICT has made possible and their impact on dental education.

1. Koper E J R, Oliver B. Representing the Learning Design of Units of Learning. Educational Technology \& Society 2004. 7: 97-111

2. Boyle T. Design for multimedia learning. Chapter 5 London: Prentice Hall, 1997

3. Millar B J, Reynolds PA, Chiodera G, Paganelli C Results of a short course on aesthetic dentistry. Proceedings of the Association of Dental Education in Europe (ADEE) 33rd Annual Meeting, 4-5 September 2007, Dublin, Ireland. Abstract pp 22.

4. Höhne S, Schumann R R. Computer-assisted learning in human and dental medicine. Int J Comput Dent 2004; 7: 159-167.

5. Gibson S B. Pedagogy and hypertext. In Strate L, Jacobson R L, Gibson S (eds) Communication and cyberspace: social interaction in an electronic environment. Creskill, New Jersey: Hampton Press Inc, 2003

6. Mason R. Using communications media in open and flexible learning. London: Kogan Page, 1994.

7. Wiesenberg F, Stacey E. Reflections on teaching and learning online: quality program design, delivery and support issues from a cross-global perspective. Distance Educ 2005; 26: 385-404.

8. King's College London Information Strategy Committee. Authoring and publication of website content procedures. London: King's College London, 2006. www.kcl.ac.uk/college/policyzone/attachments/ Style\%20guidelines.pdf. Accessed 26 March 2008.

9. Nielsen J. How users read on the web. October 1 1997. http://www.useit.com/alertbox/9710a.html. Accessed 5 May 2007.

10. Nielsen J. Be succinct! (Writing for the web). October 15 1997. http://www.useit.com/alertbox/ 9703b.html. Accessed 5 May 2007.

11. Castro E. HTML for the world wide web. Berkeley, California: Peachpit Press, 2000.

12. Entheos. Designing websites for all screen resolutions. http://www.entheosweb.com/website_design/advanced_web_design.asp. Accessed 5 May 2007.

13. Parker L. Designing websites. Case Spring Middle School, Roanoke VA. http://www.rcs.k12.va.us/ $\mathrm{csjh} /$ webpages.htm. Accessed 5 May 2007.

14. The Wisconsin Online Resource Center. A new way of thinking about learning content. Available at www. wisc-online.com. Accessed 20 February 2007.

15. Mason R. Holistic course design using learning objects. Int J Learning Technol 2006; 2: 203-215.

16. The Higher Education Academy. ACETS:Assemble, Catalogue, Exemplify, Test and Share. Special Report 8. The Higher Education Academy, 2005. ISBN 0-7017-0197-8. http://www.acets.ac.uk/ 
resources/acetspub.pdf. Accessed 27 March 2008.

17. Wiley D A. The instructional use of learning objects. Online version. reusability.org, 2000. http://www. reusability.org/read/2000. Accessed 5 May 2007.

18. RLO-CETL Cambridge website. What is the Wolfson Reward Programme? University of Cambridge, 2006. www.ucel.ac.uk/rlo-cetl/wolfson.html. Accessed 27 March 2008.

19. Caplan D. The development of online courses. In Anderson T, Elloumi F (eds) Theory and practice of online learning. pp 175-194. Athabasca University, Canada: Creative Commons, 2004
20. Joint Information Systems Committee. MLE information pack. Introducing Managed Learning Environments. www.jisc.ac.uk/whatwedo/programmes/programme_buildmle_hefe/mle_lifelonglearning_info/mle_briefingpack.aspx. Accessed 27 March 2007

21. Blackboard website. Blackboard Learning System. http://www.blackboard.com/products/academic_suite/learning_system/index. Accessed 20 February 2007.

22. Weller M. VLE 2.0 and future directions in learning environments. In Philip R, Voerman A, Dalziel J (eds) Proceedings of the First International LAMS Conference 2006: designing the future of learning pp 99-106. Sydney: LAMS Foundation, 2006. http://lamsfoundation.org/lams2006/papers.htm. Accessed 26 March 2008.

23. Junco R, Mastrodicasa J. Connecting to the net. generation: what higher education professionals need to know about today's students. pp 1-11 Washington, DC: NASPA, 2007.

24. Mason R D, Rennie F. Using Web 2.0 for learning in the community. The Internet and Higher Education 2007; 10: 96-203. 